\title{
Peculiarities of the Pontogammarus robustoides (Amphipoda, Gammaridae) Adaptive Reactions to the Water Temperature Increasing in the Model Ecosystem - Microcosm
}

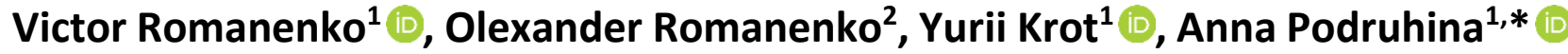

${ }^{1}$ Institute of Hydrobiology NAS of Ukraine, Geroiv Stalingrada av., 12, Kyiv, 04210, Ukraine.

${ }^{2}$ Bogomolets National Medical University, Peremogy av., 34, Kyiv, 03057, Ukraine.

\section{How to cite}

Romanenko, V., Romanenko, O., Krot, Y., Podruhina, A. (2021). Peculiarities of the Pontogammarus robustoides (Amphipoda, Gammaridae) Adaptive Reactions to the Water Temperature Increasing in the Model Ecosystem - Microcosm. Turkish Journal of Fisheries and Aquatic Sciences, 21, 365-374. http://doi.org/10.4194/1303-2712-v21_8_01

\section{Article History}

Received 23 November 2020

Accepted 28 April 2021

First Online 06 May 2021

\section{Corresponding Author}

Tel.: +380501675718

E-mail: podrugina1983@gmail.com

\section{Keywords}

Microcosm

Temperature

Gammarids

Adaptive reactions

Energy metabolism

\begin{abstract}
The crustaceans' family Gammaridae populations' adaptive reactions with a water temperature increasing to the critical values were studied in the model ecosystem the microcosm. The experiment included investigation of such indexes as population dimensional composition, precopulatory activity, number of oviparous females, embryogenesis duration, and energy metabolism at the different phases of thermocycle. Obtained data revealed optimal and critical for gammarid's viability temperature conditions of environment. It is assumed that under conditions of climate change, when water temperature sharp fluctuations take place, in the Kyiv reservoir (Dnipro River, Ukraine) coastal shallow water crustacean's family Gammaridae components of the invertebrates associations the structural and functional changes are expected. Temperature increasing to the critical values will promote the animals migration processes intensification; incapable of this animals will perish. Gammarids with ability to migrate in direction of areas with more favorable for their viability conditions will have a significant advantage.
\end{abstract}

\section{Introduction}

For natural ecosystem sustainable functioning the optimal ratio of current environmental factors is critical. An ability to maintain a dynamic balance with the environment determines populations of invertebrate and invertebrates' association existence and resilience (Perkins et al., 2015).

Taking into account that aquatic animals viability in natural conditions is determined by the complex of ecological and physiological mechanisms involved in their number, biomass, rate of development, structural and functional characteristics regulation etc. (Alimov, 2000; Romanenko et al., 2004), the use of methods that allow to model and to predict changes in biota in global climate change conditions become increasingly important (Mckee et al., 2002).

The problem of the global climate changes influence biota concerns the coastal shallow water zone invertebrates development especially (Capon, 2016; Höök et al., 2020). They are important components of benthos and periphyton biocenoses and significantly affected by environmental factors, among them temperature fluctuations, in particular temperature increasing to the animals viability critical values (Wijnhoven et al., 2003).

In order to forecast these factors, influence on biota different ecosystem models are used; among them such ecosystem model as microcosm is an accepted instrument in this branch of research (Chapman \& 
Maund, 1996; Tsirtsis \& Karydis, 1997; Campbell et al., 1999).

This work is devoted to the investigation in conditions of the model ecosystem - microcosm - the critical values water temperature increasing adaptive reactions peculiarities in representatives of the family Gammaridae known as important components of the Kyiv reservoir coastal shallow water invertebrate associations (Khilchevsky \& Grebnya, 2014).

Literature concerning influence of high water temperature on freshwater invertebrates, especially gammarids, in microcosms is very restricted (Perkins et al., 2010; Romanenko et al., 2010).

\section{Materials and Methods}

Water invertebrates of different systematic groups, filamentous algae Spirogyra sp., other associated organisms, and microbiota (Starosila, 2017) were the basis of the community in the control and experimental microcosms. Special attention was paid to gammarids and bivalves, which were taken along with natural substrates from Kyiv reservoir coastal shallow waters zone (Tolokun tract, 5054'39.7"N 30²6'46.6"E).

In the microcosm family Gammaridae representatives were the following: gammarids Pontogammarus robustoides (Sars, 1894), Dikerogammarus villosus (Sowinsky, 1894), Dikerogammarus haemobaphes (Eichwald, 1841), Echinogammarus ischnus (Stebbing, 1899); family Unionidae representatives were the following: bivalves Unio tumidus (Philipsson, 1788), Unio pictorum (Philipsson, 1788).

The invertebrate species were determined as described in the accessible references (MordukhaiBoltovskoi, 1969; Tsalolikhin, 1995, 2016) taking into account the modern nomenclature (Horton et al., 2021).

At the end of acclimatization period in the microcosm for control protocol and in the microcosm for experimental protocol the animal structural and functional states were similar.

In the microcosm gammarids physiological reactions and survivance were studied in conditions of static water temperature and in conditions of daily water temperature fluctuations also. Reproductive activity was assessed as relative precopulating animal pairs number from the total mature individuals number and as relative oviparous females number from the total females number, respectively. Sampling and samples processing were performed in accordance with generally accepted methods (Zhadin, 1960) in triplicate. The physiological state of gammarids was assessed by the rate of oxygen consumption, which was determined by the method of closed beakers (Zhadin, 1960).

To evaluate gammarids reproductive capacity the following were assessed: the relative number (quantity) of precopulating animal pairs; the relative number of fertilized females; the relative number of unfertilized females (females that did not produce offsprings). To study the reproductive effects, 6-10 precopulating individuals or an appropriate number of females and males were placed into $250 \mathrm{~cm}^{3}$ cages (the protocol was repeated two to three times). The females were moved to a separate cage after laying the eggs; the embryonic period duration was controlled there. After spawning, the females were returned to the cage comprise of males.

As an animal fodder it was used the following: filamentous algae, willow leaves, plant fodder "Tetramin ${ }^{\circledR "}$.

The model ecosystems used met the following necessary characteristics: microcosms were physically limited, self-sufficient, contained organisms of more than one trophic level; taking into account microcosm volume it was possible to extract samples from the model ecosystem without its structure and dynamic regime significant disturbances. To construct a microcosm (in particular, its abiotic component), two tanks filled with preconditioned tap water and in situ water in a ratio of 1:1 and operating in parallel were used; each tank was divided by a partition into two interconnected compartments with a water flow length of $6.7 \mathrm{~m}$ in general (Figure 1).

In the tanks water flow was produces by the mounted on a common axis blades rotation by means of an electric drive. The model ecosystem characteristics are given in the table 1 .

Obtained data were processed using Statistica 6.0 program. Markers and error bars at the figures represent average values and their standard deviations. Checking the statistically sound difference between the dimensional composition of the P.robustoides populations in the control and experimental microcosm was carried out using Pearson's $\chi^{2}$ test. Statistical significance of differences for normal distributed indexes were evaluated by Student two-sample criterion ( $t$-test for independent samples). The differences in the results were considered valid if $\mathrm{P}<0.05$.

\section{Results and Discussion}

The gammarids associations in the microcosm for control protocol and in the microcosm for experimental protocol were similar and consisted of $P$. robustoides, D. villosus, D. haemobaphes and E. ischnus representatives with the monodominance of P. robustoides ( 99\%) ones. The D. villosus individuals number did not exceed $1 \%$ of total gammarids number in the microcosm, $D$. haemobaphes and $E$. ischnus were represented by single individuals only. The different gammarides species distribution on the natural substrates in the microcosms was similar in general, though some peculiarities could be indicated also (Figure 2).

Thus, the $P$. robustoides population prefers the filamentous algae and root trees, D. villosus - the root substrate, as well as dreissena druses, $D$. haemobaphes and $E$. ischnus - bivalves clusters only. It should be noted 
Table 1. Morphometric and hydrological characteristics of the model ecosystem

\begin{tabular}{lccccc}
\hline Length, $\mathrm{m}$ & Depth, $\mathrm{m}$ & Bottom surface area, $\mathrm{m}^{2}$ & Surface walls area, $\mathrm{m}^{2}$ & Water volume, $\mathrm{m}^{3}$ & Flow rate, $\mathrm{m} / \mathrm{s}$ \\
\hline 3.35 & 0.27 & 1.27 & 5.21 & 0.44 & 0.05 \\
\hline
\end{tabular}

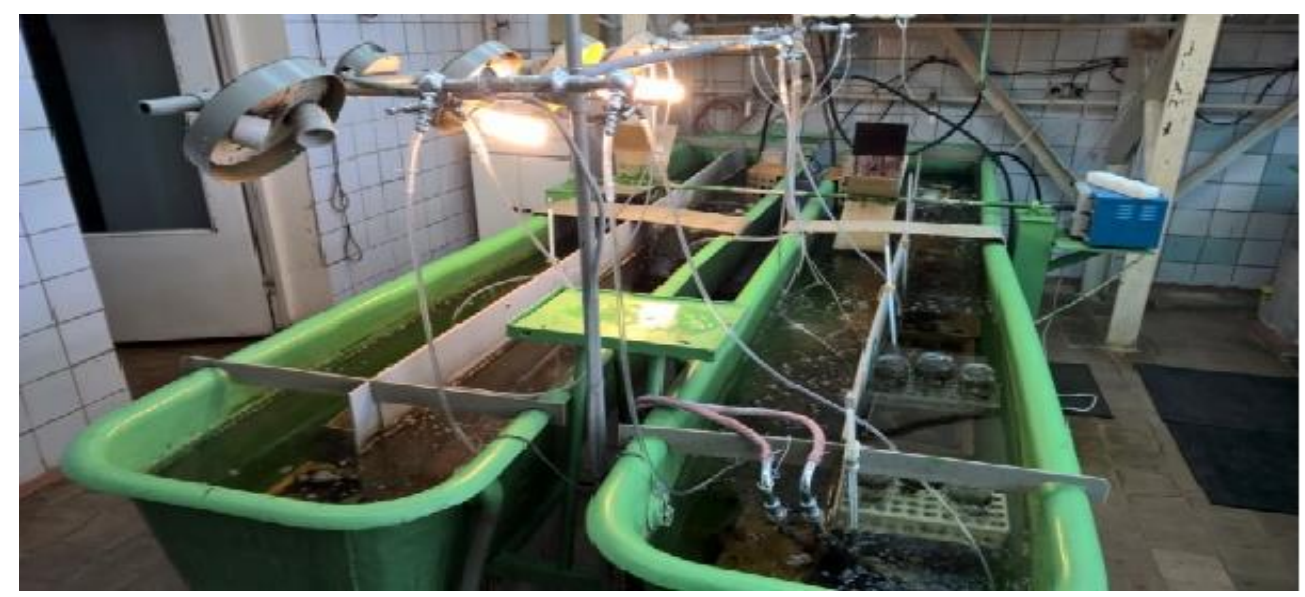

Figure 1. The model ecosystem - microcosm.
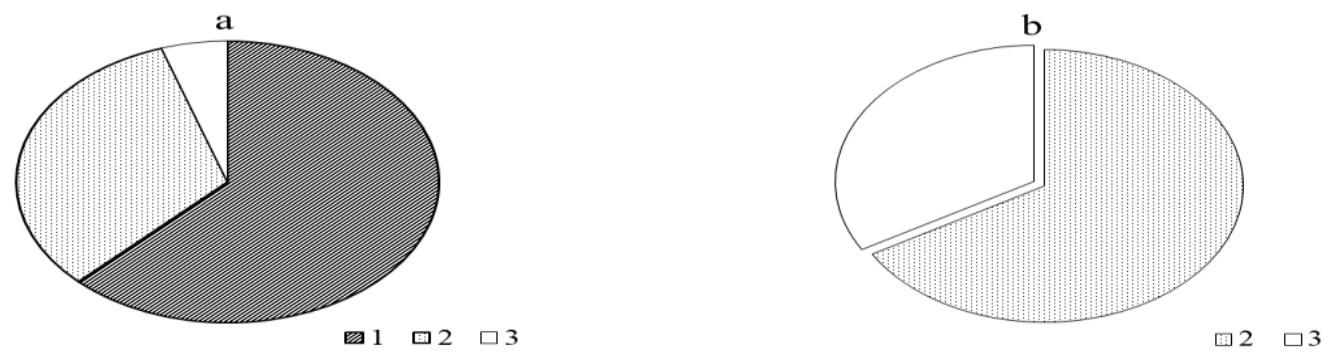

Figure 2. Gammarids $P$. robustoides (a) and $D$. villosus (b) distribution on the different natural substrates in the model ecosystem ( 1 - filamentous algae, 2 - tree roots, 3 - mollusks).

D. villosus individuals and P. robustoides individuals separate localization in the roots of trees; it is correspond to the mosaic mode of these animals distribution that we observed in the Kyiv reservoir coastal shallow water zone during gammards sampling (Romanenko et al., 2020).

The $P$. robustoides population was characterized by a predominance of the younger size-age group animals (the share - 54\%) and the middle size-age group animals (the share - 38\%). The younger age group individuals were found both in the root substrate and in the filamentous algae, and individuals longer than 10 $\mathrm{mm}$ (the share did not exceed $8 \%$ ) prefer root trees localization. The number of precopulating pairs reached $7 \%$, and females with eggs $-44 \%$. The initial state of the population corresponded to the phase of active reproduction. A small population of $D$. villosus was represented by adult individuals $10-14 \mathrm{~mm}$ long; among them oviparous females were not found.

In the control microcosm the temperature was $25 \pm 0.5^{\circ} \mathrm{C}$. In the experimental microcosm the temperature regime dynamics was approximately similar as one in the Kyiv reservoir coastal shallow water zone invertebrates' distribution areas during periods of these areas significant warming (Romanenko et al., 2020) and included the following stages: 1 ) temperature increasing as $1^{\circ} \mathrm{C} /$ day $\left(1^{\text {st }}-2^{\text {nd }}\right.$ day of observation, $6^{\text {th }}-$ $8^{\text {th }}$ day of observation); 2 ) temperature stabilization at subcritical value $27 \pm 0.5^{\circ} \mathrm{C}\left(2^{\text {nd }}-5^{\text {th }}\right.$ day of observation), at critical value $30 \pm 0.5^{\circ} \mathrm{C}\left(8^{\text {th }}-13^{\text {th }}\right.$ day of observation), and at critical value $32 \pm 0.5^{\circ} \mathrm{C}\left(14^{\text {th }}\right.$ day of observation) also; 3 ) temperature decreasing from $32 \pm 0.5^{\circ} \mathrm{C}$ to initial value $25 \pm 0.5^{\circ} \mathrm{C}\left(14^{\text {th }}-16^{\text {th }}\right.$ day of observation); 4) temperature stabilization at initial value $25 \pm 0.5^{\circ} \mathrm{C}\left(16^{\text {th }}-24^{\text {th }}\right.$ day of observation) (Figure 3 ).

The processes determining aquatic environment quality in the control microcosm and in the experimental microcosm were similar in general (Figure 4).

In the control microcosm and in the experimental microcosm nitrogen-containing compounds transformation activation was found soon after observation beginning. On the $2^{\text {nd }}$ day of water temperature increasing from $25 \pm 0.5^{\circ} \mathrm{C}$ to $28.0 \pm 0.5^{\circ} \mathrm{C}$ in the respective microcosm the ammonium nitrogen content stabilized and subsequently did not exceed value $0.1 \mathrm{mg} / \mathrm{dm}^{3}$. Maximum $\mathrm{NO}_{2}{ }^{-}$value $\left(\sim 2.1 \mathrm{mgN} / \mathrm{dm}^{3}\right)$ was registered on the $2^{\text {nd }}$ day of 


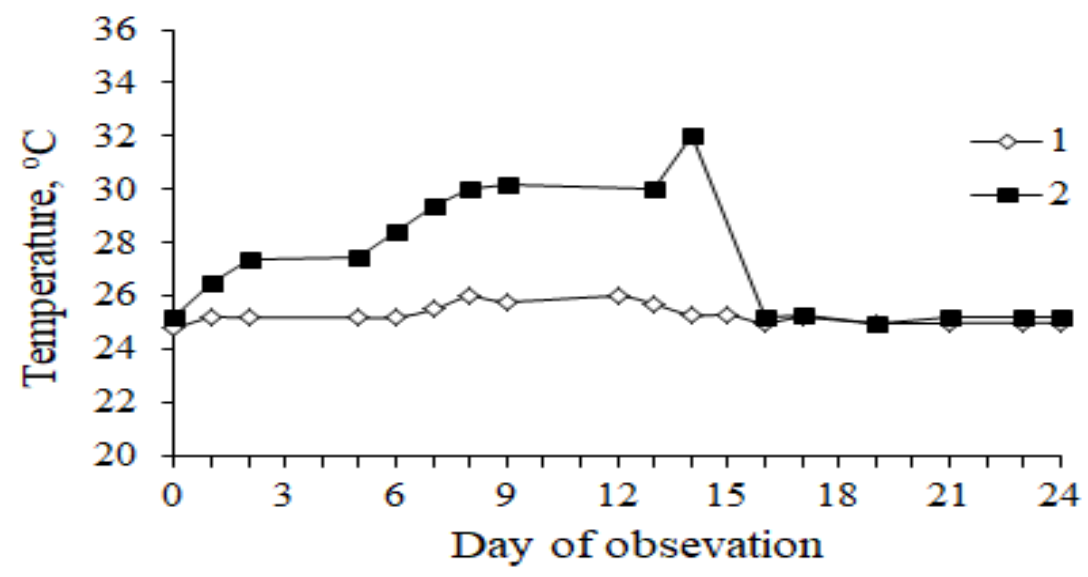

Figure 3. Temperature regime in the microcosms: 1 - control; 2 - experiment.
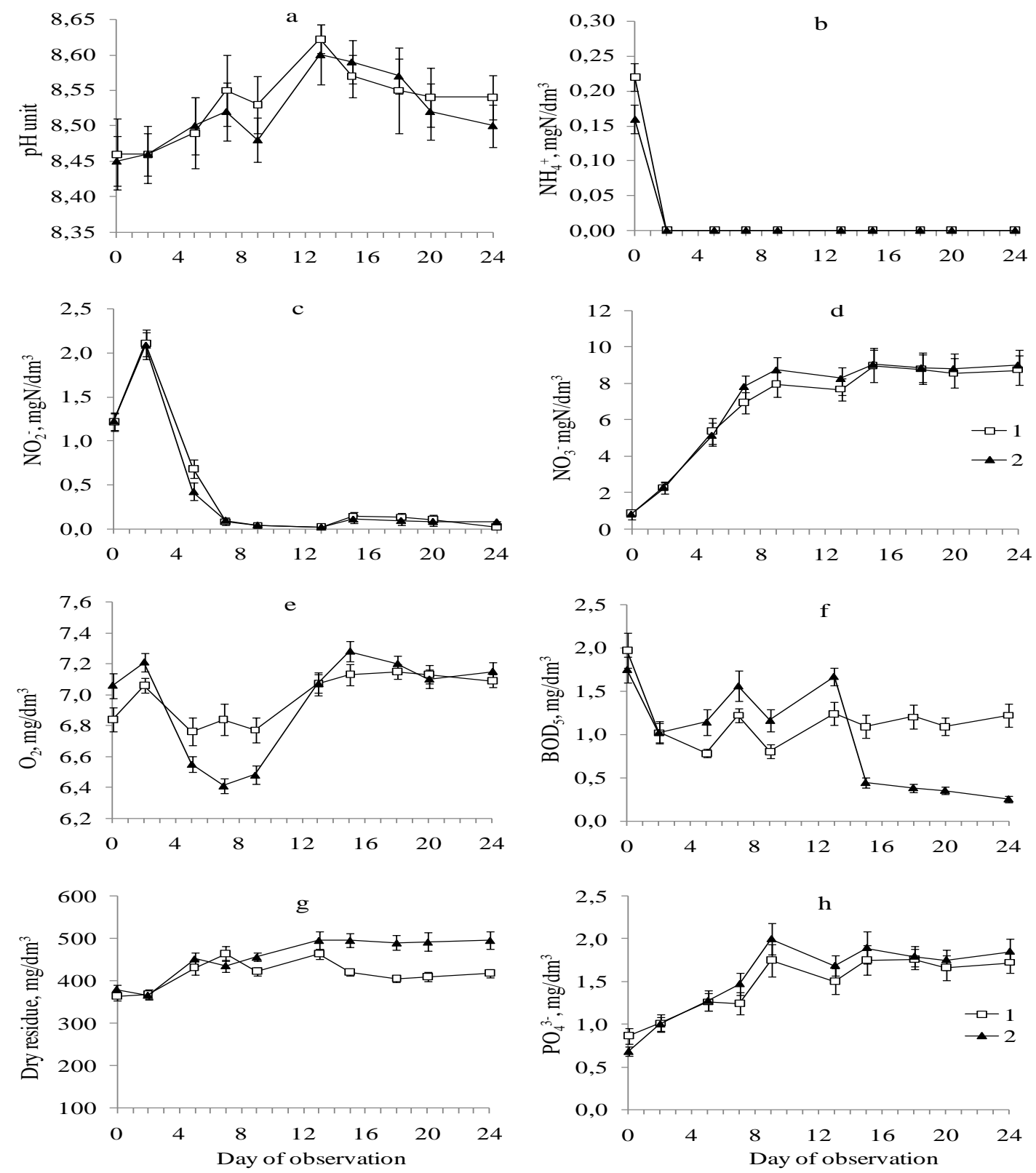

Figure 4. The aquatic environment quality in the model ecosystem (1 - control microcosm, 2 - experimental microcosm): a - pH; $\mathrm{b}-\mathrm{NH}_{4}{ }^{+}, \mathrm{c}-\mathrm{NO}_{2}{ }^{-}, \mathrm{d}-\mathrm{NO}_{3}{ }^{-}, \mathrm{e}-$ concentration of dissolved $\mathrm{O}_{2}$ in water, $\mathrm{f}-$ biological oxigen demand $\left(\mathrm{BOD}_{5}\right), \mathrm{g}-\mathrm{dry}$ residue, $\mathrm{h}-$ $\mathrm{PO}_{4}{ }^{3-}$ 
observation. Afterwards, until $7^{\text {th }}$ day, $\mathrm{NO}_{2}{ }^{-}$value rapidly decreased with relative stabilization of $\mathrm{NO}_{2}{ }^{-}$value from the $7^{\text {th }}$ day of observation at the level of $0.02-0.14$ $\mathrm{mgN} / \mathrm{dm}^{3}$. Water temperature increasing to $30^{\circ} \mathrm{C}$ contributed to the following in the microcosm: 1) $\mathrm{NO}_{3}{ }^{-}$, $\mathrm{PO}_{4}{ }^{3-}, \mathrm{BOD}_{5}$, dry residue levels gradual increasing; 2 ) $\mathrm{pH}$ and concentration of dissolved $\mathrm{O}_{2}$ in water gradual decreasing with further reaching the plateau level; 3) the activity of organic mineralization gradual increasing when water temperature is more than $27^{\circ} \mathrm{C}$. Further water temperature increasing to $32{ }^{\circ} \mathrm{C}\left(14^{\text {th }}\right.$ day of observation) contributed to the sharp decreasing in the microcosm $\mathrm{BOD}_{5}$ level, though trends concerning other mentioned above indicators persisted in general.

Since $P$. robustoides association monodominance in the microcosm, structural and functional state of $P$. robustoides representatives there were investigated.

There were no principal differences in the $P$. robustoides population size and age parameters trends in the control microcosm and in the experimental microcosm (Figure 5).

Thus, it was typical of individuals 5-12 mm long presence in the control microcosm during the $2^{\text {nd }}-12^{\text {th }}$ day of observation (temperature $25 \pm 0.5^{\circ} \mathrm{C}$ ); the share of such individuals in the population was $80-91 \%$. For comparison, it was also typical of individuals 5-12 mm long presence in the experimental microcosm during the $2^{\text {nd }}-12^{\text {th }}$ day of observation (temperature range $27-$ $30{ }^{\circ} \mathrm{C}$ ); the share of such individuals in the population was $77-85 \%$, difference to control values was statistically non-significant according to $\chi^{2}$ test $(p=$ 0.26).

In the experimental microcosm on the $2^{\text {nd }}$ day of observation body length more than $14 \mathrm{~mm}$ (15-16 mm) individuals were observed and the share of such individuals in the population was $0.7 \%$, on the $5^{\text {th }}$ day of observation (temperature $27 \pm 0.5^{\circ} \mathrm{C}$ ) body length more than $14 \mathrm{~mm}(15-16 \mathrm{~mm})$ individuals $-4,5 \%$, on the $13^{\text {th }}$ day of observation (temperature $30 \pm 0.5^{\circ} \mathrm{C}$ ) $-7.7 \%$, on the $14^{\text {th }}$ day of observation (temperature $32^{\circ} \mathrm{C}$ ) $-7.5 \%$, on the $23^{\text {rd }}$ day of observation (temperature stabilization at initial value $25 \pm 0.5^{\circ} \mathrm{C}$ ) $-11.7 \%$. For comparison, in the control microcosm body length more than $14 \mathrm{~mm}$ (15-16 mm) individuals were found firstly on the $7^{\text {th }}$ day of observation (temperature $25 \pm 0.5^{\circ} \mathrm{C}$ ) and the share of such individuals in the population was $1.6 \%$, on the $13^{\text {th }}$ day of observation (temperature increasing to $\left.26.0 \pm 0.5^{\circ} \mathrm{C}\right)-4.9 \%, \chi^{2} p=0.09$.

In the control microcosm on the $16^{\text {th }}$ day of observation newly reproduced body length less than 2 $\mathrm{mm}$ individuals were determined and the share of such individuals in the population was 55\%. For comparison, in the experimental microcosm on the last stage of research protocol (temperature stabilization at initial value $\left(25 \pm 0.5^{\circ} \mathrm{C}\right)$ newly reproduced body length less than $2 \mathrm{~mm}$ individuals were determined but the share of such individuals in the population was $21.7 \%$ only twice less than in the control, $t$-test $\mathrm{P}<0.01$. This date indicates a decrease in the intensity of reproduction in gammarids after their exposition to extreme temperatures.

Aquatic animals' behavioral reactions reflect organism physiological responses if environmental conditions changes take plase. Investigation of the $P$. robustoides precopulatory activity reveales a stimulating effect of a gradual temperature increasing from $25^{\circ} \mathrm{C}$ to $27^{\circ} \mathrm{C}$ as $1{ }^{\circ} \mathrm{C} /$ day ( $2^{\text {nd }}$ day of observation) (Figure 6a).

In particular, it was shown in the experimental microcosm the number of gammarids precopulating pairs growth by 1.5 times in comparison with the control before temperature increasing, $t$-test $P<0.05$. Similar trend was detected in the control microcosm with temperature increase to $25.7^{\circ} \mathrm{C}$ (on the $7^{\text {th }}$ day of observation) when precopulating pairs share growth by 1.7 times, $t$-test $\mathrm{P}<0.01$.

Further temperature increasing to $30^{\circ} \mathrm{C}$ in the exerimental microcosm provoces gammarids precopulatory activity depression: the 32\% ( $t$-test $\mathrm{P}>0.05)$ precopulating pairs number decreasing on the $9^{\text {th }}$ day of observation and the $86 \%$ ( $t$-test $\left.P<0.01\right)-$ on the $14^{\text {th }}$ day of observation compared with the control before temperature increasing, respectively. Precopulating pairs were not found at the temperature $32{ }^{\circ} \mathrm{C}$ practically.

Visual examination revealed acute motor activity depression of gammarids during temperature increasing from $28^{\circ} \mathrm{C}$ to $30^{\circ} \mathrm{C}\left(7^{\text {th }}-9^{\text {th }}\right.$ day of observation) and later to $32^{\circ} \mathrm{C}\left(13^{\text {th }}-14^{\text {th }}\right.$ day of observation). A less pronounced animals suppressive reaction was registrated in conditions of a stable exerimental microcosm temperature $30{ }^{\circ} \mathrm{C}\left(10^{\text {th }}\right.$ day of observation).

It was detected gammarids precopulatory activity increasing in the experimental microcosm on the $16^{\text {th }}$ day of observation during temperature decreasing to initial value $25 \pm 0.5^{\circ} \mathrm{C}$ : the share of of individuals in pairs reached $50.5 \%$. In the control microcosm at the same period of obsevetion, similar phenomenon was observed also. The above indicates the possibility of influencing the reproductive activity of gamarids in the both microcosms factors others than temperature, such as seasonal cyclicity, for example.

An important indicator of the gammarids population reproductive status is the oviparous females number. On the $2^{\text {nd }}$ day of observation (temperature increasing as $1{ }^{\circ} \mathrm{C} /$ day) the share of females with eggs in the experimental microcosm exceeded the control level by $20 \%, t$-test $P>0.05$; possibly, it can be explained as stimulating effect of the temperature increasing to subcritical value $\left(27^{\circ} \mathrm{C}\right)$, likely (Figure $\left.6 \mathrm{~b}\right)$. On the $5^{\text {th }}$ day of observation (temperature stabilization at subcritical value $27 \pm 0.5^{\circ} \mathrm{C}$ ) and on the $14^{\text {th }}$ day of observation (critical temperature $32 \pm 0.5^{\circ} \mathrm{C}$ ) the share of females with eggs in the experimental microcosm was in the range of $4.3-4.6 \%$ only, this indicator values were 2.8 times and 8.5 times less than in control, respectively ( $t$ test $\mathrm{P}<0.01$ ). The received data can be explained by the negative impact of the mentioned above ecological 

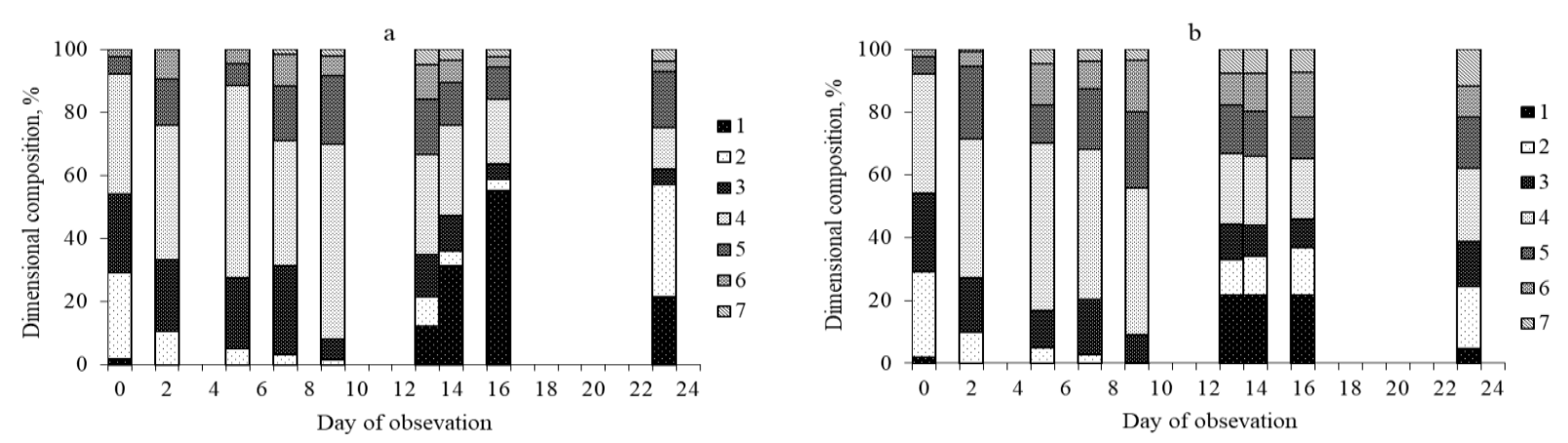

Figure 5. Dimensional composition of the $P$. robustoides population in the model ecosystem $(a-$ control microcosm, $b-$ experimental microcosm); 1-7 - individuals body length groups: $<3.0 \mathrm{~mm}$ (1); 3.1-5.0 mm (2); 5.1-7.0 mm (3); 8-10 mm (4); 11$12 \mathrm{~mm}(5) ; 13-14 \mathrm{~mm}(6) ; 15-16 \mathrm{~mm}$ (7).
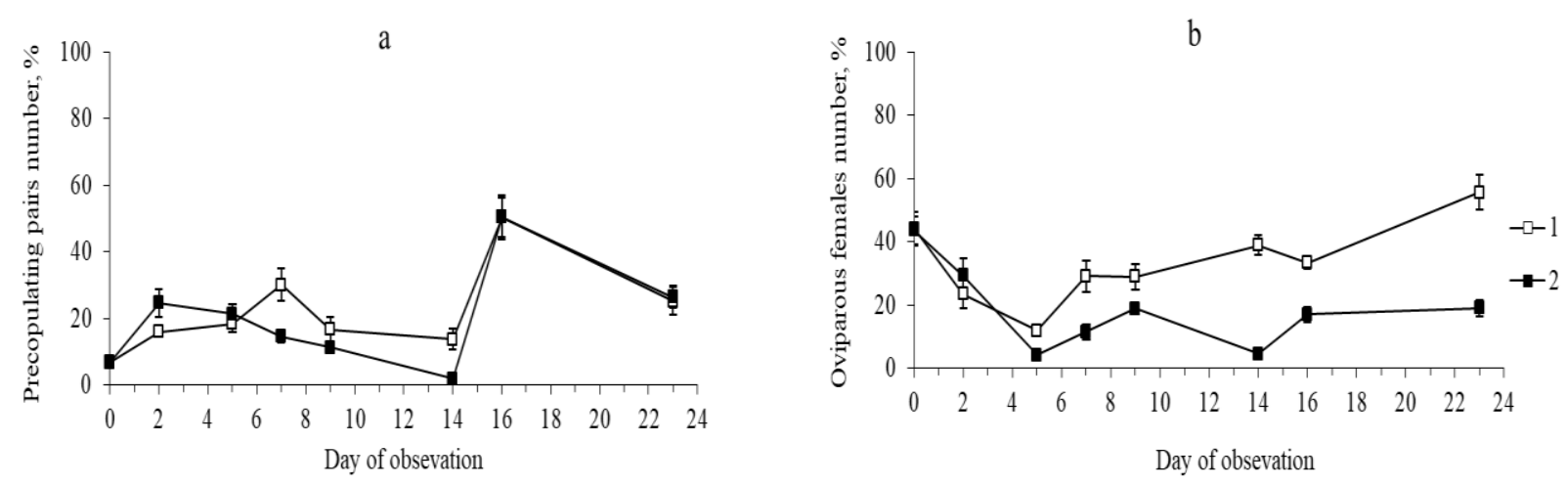

Figure 6. Precopulatory activity (a) and the number of oviparous females (b) of $P$. robustoides at different stages of the temperature regime in the microcosm ( 1 - control microcosm, 2 - experimental microcosm).

factor on the gammarids viability, likely. Similar situation was detected as result of temperature increasing to $32{ }^{\circ} \mathrm{C}$ in the experimental microcosm.

On the $16^{\text {th }}$ day of observation (temperature decreasing to initial value $25 \pm 0.5^{\circ} \mathrm{C}$ ) the share of females with eggs in the experimental microcosm was $17.2 \%$. For comparison, in the control microcosm from the $7^{\text {th }}$ day of observation the share of females with eggs increased to the value $29-39 \%, t$-test $\mathrm{P}<0.05$.

Thus, the share of oviparous females at the experimental microcosm temperature values over $27^{\circ} \mathrm{C}$, as well as after further temperature reduction to $25^{\circ} \mathrm{C}$, was $2.1-4.2$ times lower than in control, $t$-test $\mathrm{P}<0.01$; it is indicating gammarids reproduction ability depression as a result of the heat stress in their organisms.

An important indicator of the gammarids vital activity is the embryogenesis duration. There was no statistically sound difference in this parameter in the control microcosm ( $5.3 \pm 0.3$ days) and the experimental microcosm ( $5.5 \pm 0.3$ days) in the the following period of observation: $1^{\text {st }}$ day $-5^{\text {th }}$ day (note, in the experimental microcosm temperature was increased from from $25^{\circ} \mathrm{C}$ to $27^{\circ} \mathrm{C}$ ). (Figure 7 ).

In the experimental microcosm on the $7^{\text {th }}$ day $-9^{\text {th }}$ day of observation, when temperature was increased gradually from $28{ }^{\circ} \mathrm{C}$ to $30^{\circ} \mathrm{C}$, and later on, when temperature was increased to $32{ }^{\circ} \mathrm{C}$, the considerable growth of embryogenesis duration was detected as the result of model ecosystem temperature reaching crical value, what reflects experimental microcosm specific conditions negative impact for the organism development. With the same number of precopulating pairs, the efficiency of the reproduction process in the control microcosm was $100 \%$, but in the experimental microcosm - $50 \%$ only. The manifestations of the temperature crical value gammarids embryogenesis negative impact included the following in particular: embryogenesis prolongation (9.3 \pm 0.1 days, what was $25 \%$ longer than in control, $t$-test $\mathrm{P}<0.05)$, congenital malformations (observed in the $50-60 \%$ clutches).

If fertilization took place immediately after temperature decreasing to the control value the embryogenesis duration accelerated and was detected as $7.5 \pm 0.4$ days in the experimental microcosm, though this value was still $12 \%$ longer than in control $6.6 \pm 0.4$ days, $t$-test $\mathrm{P}<0.05$.

Based on the analysis of the peculiarities of the experimental microcosm population P. robustoides individuals size and age structures it was concledud that temperature increasing is a factor what stimulates animals growth (Figure 8).

In the experimental microcosm on the $8^{\text {th }}$ day of observation (after temperature increasing from $25^{\circ} \mathrm{C}$ to 
$30{ }^{\circ} \mathrm{C}$ ) the $P$. robustoides population individuals absolute body length gain was $65.3 \%$ more and absolute body weight gain was $107.6 \%$ more, than the same day of observation gammarids respective characters in the control microcosm, $t$-test $\mathrm{P}<0.05$. In the experimental microcosm on the $14^{\text {th }}$ day $-24^{\text {th }}$ day period of observation (characterized by the temperature value $25^{\circ} \mathrm{C}$ ) the $P$. robustoides population individuals daily body length gain was $30 \%$ more and daily body weight gain was $230 \%$ more, than the same period of observation gammarids respective characters in the control microcosm, $t$-test $\mathrm{P}<0.05$ and 0.01 respectively.

In the experimental microcosm on the $8^{\text {th }}$ day $13^{\text {th }}$ day period of observation (characterized by the temperature value $30 \pm 0.5^{\circ} \mathrm{C}$ ) the $P$. robustoides population individuals daily body length gain was $45.2 \%$ less and daily body weight gain was $54.2 \%$ less, than the same period of observation gammarids respective characters in the control microcosm, $t$-test $P<0.01$. Suppression of the gammarids growth rate described above indicates that both the temperature approximation to the critical values of the tolerance range for $P$.robustoides $\left(32^{\circ} \mathrm{C}\right)$ and the water environment respective temperature long-term maintaining negatively influence gammarids population representatives vitality; it is correlate with results our of previous research also (Romanenko et al. 2014 a, 2014 b).

An important indicator of the gammarid vital activity is the organism oxygen consumption rate. This indicator is used for the animal adaptive capacity to environmental conditions characterization also. In order to detemine the gammarids oxygen consumption rate the body length $10-12 \mathrm{~mm} P$. robustoides individuals were used. It was found more than 2 times increase in the organism oxygen consumption rate in both the control microcosm and the experimental microcosm gammarids during period of observation ( $t$-test $P<0.01$ ), as Figure 9 illustarates.

In particular, in the control microcosm relatively stable temperature conditions $\left(25 \pm 0.5^{\circ} \mathrm{C}\right)$ the animal oxygen consumption rate gradually increased 2.9 times ( $t$-test $P<0.01)$ in the period $1^{\text {st }}$ day $-9^{\text {th }}$ day of observation and then was stable in general.

In the experimental microcosm period $1^{\text {st }}$ day $-2^{\text {nd }}$ day of observation, when temperature increasing from $25^{\circ} \mathrm{C}$ to $27 \pm 0.5^{\circ} \mathrm{C}$ as $1{ }^{\circ} \mathrm{C} /$ day took pace, the animal oxygen consumption rate gradually increased more than 2 times ( $t$-test $P<0.01)$, but during further peirod of relatively stable temperature conditions $\left(27 \pm 0.5^{\circ} \mathrm{C}\right)$ the tendency to its decreasing was registered and on the $5^{\text {th }}$ day of observation the experimental microcosm animal oxygen consumption rate was almoust similar to the control microcosm one.

There were no statistically sound changes in the experimental microcosm period $5^{\text {th }}$ day $-8^{\text {th }}$ day of observation (when temperature increasing from $27^{\circ} \mathrm{C}$ to $30^{\circ} \mathrm{C}$ as $1{ }^{\circ} \mathrm{C} /$ day took pace) animal oxygen consumption rate, though it was $14.5 \%$ ( $t$-test $P<0.05$ ) less than in the control microcosm animal. Note, experimental microcosm gammarids acute motor activity depression was odserved during this period as was mentioned above.

In the experimental microcosm period $8^{\text {th }}$ day $-13^{\text {st }}$ day of observation with relatively stable temperature conditions $\left(30 \pm 0.5^{\circ} \mathrm{C}\right)$ the animal oxygen consumption rate was less than in the control microcosm animal during the same period of observation (at the period begining $-38.3 \%$ less, at the period ending $-25.4 \%$ less, both $t$-test $\mathrm{P}<0.01)$. Similar situation was typical of animal oxygen consumption rate by experimental microcosm animal at the $14^{\text {th }}$ day of observation (temperature $32^{\circ} \mathrm{C}$ ).

After temperature decreasing from $32{ }^{\circ} \mathrm{C}$ to initial value $25 \pm 0.5^{\circ} \mathrm{C}$ and stabilization at this level $\left(16^{\text {th }}-24^{\text {th }}\right.$ day of observation) the experimental microcosm gammarid oxygen consumption rate was similar to the control microcosm one.

\section{Conclusions}

The experimental data received in conditions of the model ecosystem demonstrate the gammarids important vital processes temperature influence peculiarities, including their dependens on the range of current temperatures, ecologic factor (temperature) magnitude and its changes speed, as well as gammarid species ecophysiological characters.

It was typical of both for the control microcosm and for the experimental one the Pontogammarus robustoides association monodominance - this species individual manifests expressive adaptive reactions in responce to the water temperature fluctuations (to the temperature changes definite dynamics; to the temperature stabilization at definite subcritical value or definite critical value). More over, in the model ecosystem specific substrates types' preferability by gammarids was in correspondance with these animals habitual localization in the Kyiv reservoir coastal shallow water zone natural conditions and had a mosaic character in our investigation also.

The useage of microcosm gave us a unique possibility to pick up concrete gammarids reactions to the even small changes in the values of such important ecological factor as water temperature, for example: 1) intensification of the growth, development, reproduction and important for the energy metabolism procecess, when water temperature was up to $27^{\circ} \mathrm{C} ; 2$ ) somewhat slowing down the growth and reproductive activity, when water temperature was within $27-28^{\circ} \mathrm{C}$; 3) declining of the motor activity and important for the energy metabolism procecess, and reproductive capacity suppressing (fertilized female individuals number decreasing, embryogenesis duration increasing), when water temperature interval was 29 $30{ }^{\circ} \mathrm{C}$. It is necessary to emphasize the observation of the embryos structure violation cases in condition of the microcosm temperature value $30^{\circ} \mathrm{C}$. The temperature 


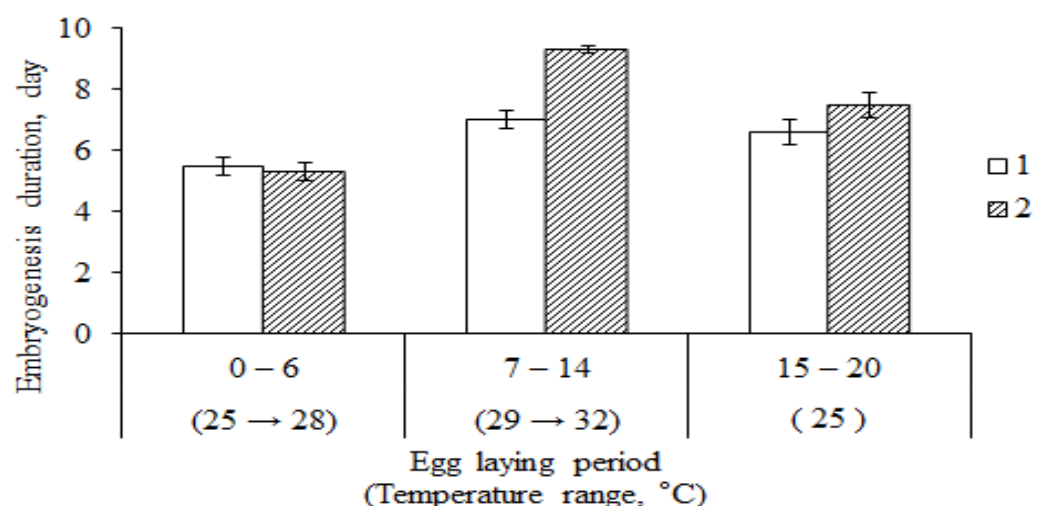

Figure 7. Embryogenesis duration in $P$. robustoides individuals in the model ecosystem at different stages of the thermocycle (1 control microcosm, 2 - experimental microcosm).
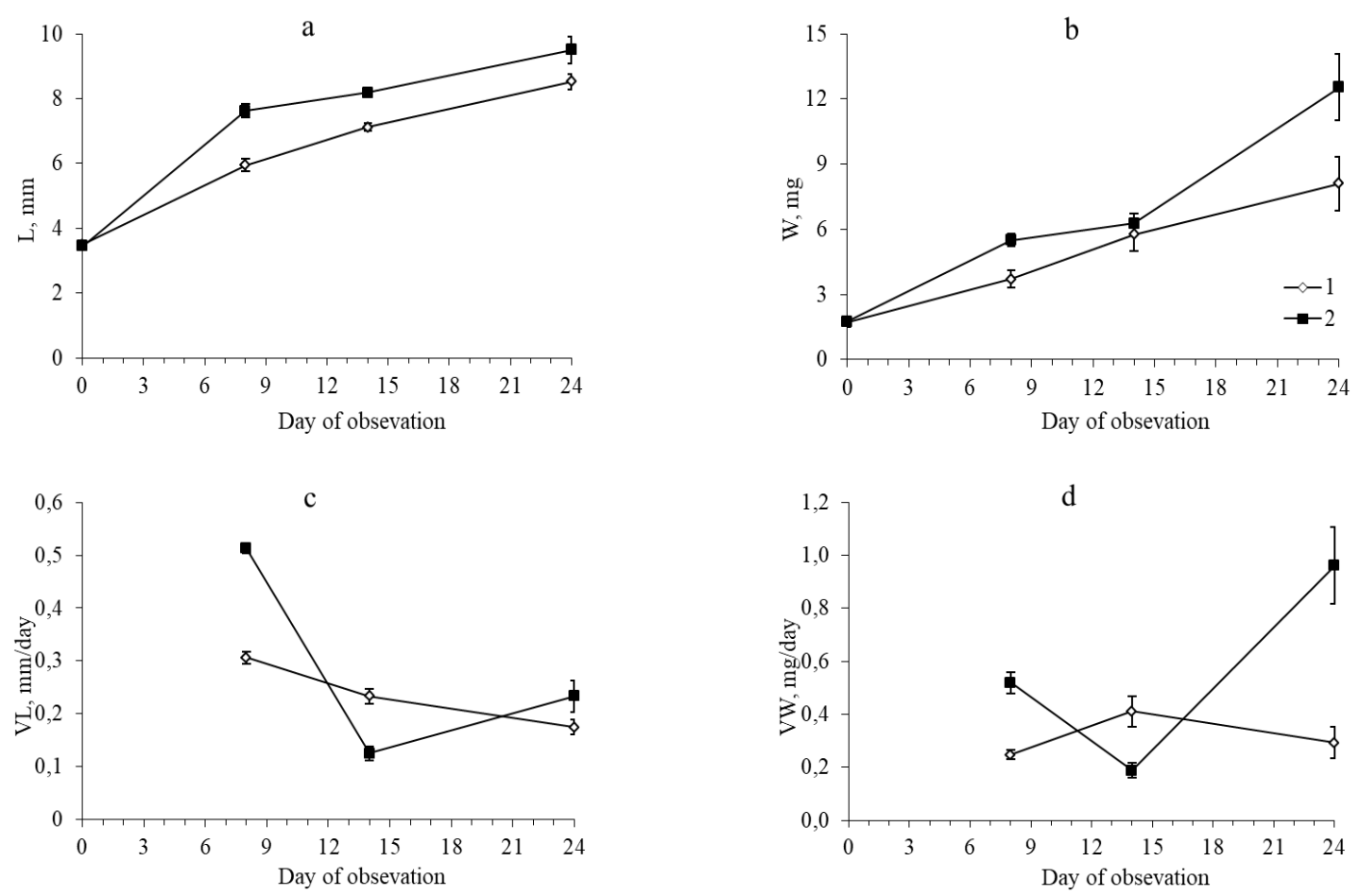

Figure 8. Body length (a), body mass (b) body length growth rate (c) body mass growth rate (d) of $P$. robustoides individuals in the model ecosystem at different stages of the temperature regime (1 - control microcosm, 2 - experimental microcosm).

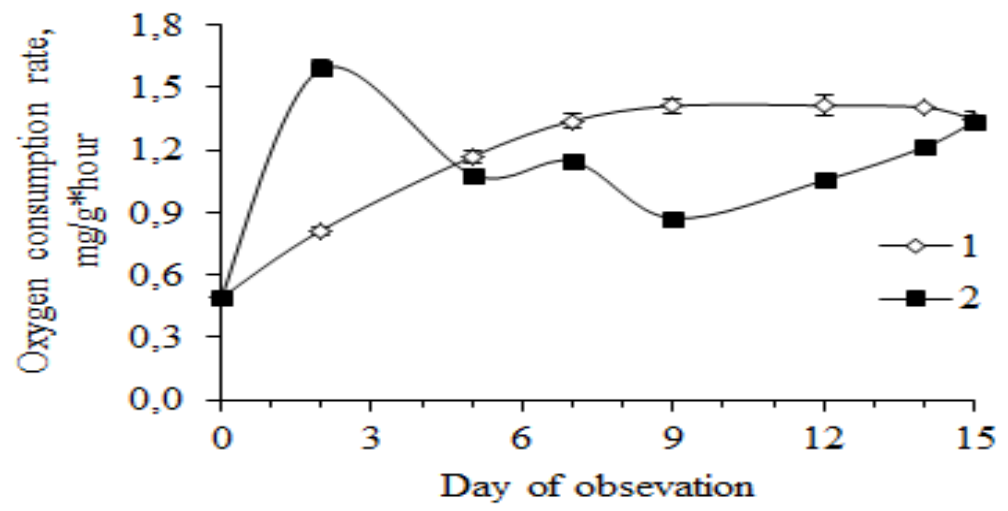

Figure 9. The rate of oxygen consumption by $P$. robustoides individuals in the model ecosystem ( 1 - control microcosm, 2 experimental microcosm). 
value $32{ }^{\circ} \mathrm{C}$ can be considered as critical value for $P$. robustoides individuals vitality. It is necessary to stress that the gammarids most intensive, so called sharp, depressive reactions are typical of at the begining the water temperature rapid increasing from $30{ }^{\circ} \mathrm{C}$ to $32{ }^{\circ} \mathrm{C}$, and they become less pronounced after temperature value stabilization.

A comparative analysis of the reactions of the gammarids to the water temperature changes revealed these organisms peculiarities in the strategies of adaptation to environmental conditions. For example, $P$. robustoides individuals are characterized by the expressed sensitivity to the environmental conditions changes, by the metabolism intensification, and by the quiet long term of adaptation (if to compare terms of adaptation in other gammarids species investigated); Dikerogammarus villosus individuals, Dikerogammarus haemobaphes individuals and Echinogammarus ischnus individuals were not adapted to the model ecosystem conditions accordingly to this research data.

Taking into account described above it is possible to assume that in the coastal shallow water zone natural conditions temperature value increasing to the critical one is an ecological factor what promotes gammarid association individuals vertical and horizontal migratons to areas with more favorable conditions, otherwise animals will be perished. Among gammarids species described in this work the privilege is expected for animals what in natural conditions are able to migrate considerable distance and depth, namely $D$. haemobaphes and $E$. ischnus individuals.

\section{Ethical Statement}

Research was planned and carried out taking into account the "Animal Research: Reporting of In Vivo Experiments» (ARRIVE) guidelines and generally internationally recognized documents of bioethics. Research Ethical Approval was not sought because the scientific usage of such invertebrates as crustaceans of the family Gammaridae and bivalves of the family Unionidae is not regulated by respective legal and ethical framework.

\section{Funding Information}

This work was supported by the National Academy of Sciences of Ukraine, fundamental research program (registration number 0118U003541).

\section{Author Contribution} article.

All authors made an equal contribution to the

\section{Conflict of Interest}

The authors declare no conflict of interest.

\section{References}

Alimov, A. F. (2000). Elements of the theory of functioning of aquatic ecosystems. Nauka.

Campbell, P.J., Arnold, D.J.S, Brock, T.C.M., Grandy, N.C., Heger, W., Heimbach, F., Maund, S.J., \& Streloke, M. E. (1999). Guidance Document on Higher-tier Aquatic Risk Assessment for Pexticides (HARAP). A SETAC-Europe Publication.

Capon, S. (2016). Climate change impacts on coastal freshwater ecosystems and biodiversity. CoastAdapt Impact Sheet 4, National Climate Change Adaptation Research Facility, Gold Coast.

Chapman, P.F. \& Maund, Sj. (1996). Considerations for the experimental design of aquatic mesocosm and microcosm studies. In: Techniques in Aquatic Toxicology. GK Ostrander (ed.) pp 657-673, CRC Lewis Publishers, Florida.

Höök, T., Foley, C., Collingsworth, P., Dorworth, L., Fisher, B., Hoverman, J., LaRue, E., Pyron, M., Tank, J. (2020). An assessment of the potential impacts of climate change on freshwater habitats and biota of Indiana, USA. Climatic Change 163, 1897-1916. https://doi.org/10.1007/s10584-019-02502-w

Horton, T., Lowry, J., DeBroyer, C., Bellan-Santini, D., Coleman, C.O., Corbari, L., Costello, M.J., Daneliya, M., Dauvin, J.C., Fišer, C., Gasca, R., Grabowski, M., Guerra-García, J.M., Hendrycks, E., Hughes, L., Jaume, D., Jazdzewski, K., Kim, Y.-H., King, R., \& Zeidler, W. (2021). WorldAmphipodaDatabase. Echinogammarus ischnus (Stebbing, 1899). https://www.marinespecies.org/amphipoda/aphia.php $? p=$ taxdetails\&id $=490104$.

Khilchevsky, V.K., Grebnya, V.V. (2014). Water Fund of Ukraine: Artificial reservoirs - reservoirs and ponds. Kyiv: Interpress.

Mckee, D., Atkinson, D., Collings, S., Eaton, J., Harvey, I., Heyes, T., Hatton, K., Wilson, D., \& Moss, B. (2002). Macrozooplankter responses to simulated climate warming in experimental freshwater microcosms. Freshwater biology, $\quad 47 \quad$ (8), $1557-1570$ https://doi.org/10.1046/j.1365-2427.2002.00878.x

Mordukhai-Boltovskoi, F. D. (Ed.) (1969). Key to fauna of the Black Sea and the Azov Sea. Vol. 2, pp. 2-536.

Perkins, D. M., McKie, B. G. \& Woodward, G. (2010). Environmental warming and biodiversity-ecosystem functioning in freshwater microcosms: partitioning the effects of species identity, richness and metabolism. Advances in ecological research, 43, 177-209. https://doi.org/10.1016/B978-0-12-385005-8.00005-8

Perkins, D.M, Bailey, R.A, \& Woodward, G. (2015). Higher biodiversity is required to sustain multiple ecosystem processes across temperature regimes. Global Change Biology. 21(1), 396-406.

https://doi.org/10.1111/gcb.12688

Romanenko, V. D. (2004). Fundamentals of hydroecology. Genesis.

Romanenko, V. D., Krot, Yu. G. \& Podrugina, A. B. (2014). Resistance of gammarids Pontogammarus robustoides and Chaetogammarus ischnus (Crustacea: Amphipoda) to elevation of temperature of the aquatic medium. Hydrobiological Journal, 50(3), 55-63. https://doi.org/10.1615/hydrobj.v50.i3.60.

Romanenko, V. D., Krot, Yu.G., \& Podrugina, G. B. (2020). Peculiarities of adaptation of Gammaridae of the 
reservoirs' littoral zone to water temperature increase. Hydrobiological Journal, 56(3), 3-12. https://doi.org/10.1615/HydrobJ.v56.i3.10.

Romanenko, V.D., Krot, Yu.G., \& Podrugina, A.B. (2014). Resistance of gammarids Pontogammarus robustoides (Sars) (Crustacea: Amphipoda) to winter temperature of the water medium. Marine Ecological Journal, 13(2), 6369.

Romanenko, V.D., Krot, Yu.G. \& Lekontseva, T.I. (2010). Features of the function of draysen-hamaride grouping in the minds of the microcosm: structural-functional characteristics of the group of draysen and hamarid. The scientific issues of Ternopil Volodymyr Hnatiuk National Pedagogical University. Ser.: Biology. Specialiss. "Hydroecology", 43(2), 293-296.

Starosila, Ye.V. (2017). Ecological-trophic structure of bacterioplankton in the experiment conditions with gamarids group in the fluctuation temperature regime.
Ternopil Bioscience - 2017: Materials of the conference, 294-297.

Tsalolikhin, S. Ya. (Ed.). (1995). Key to freshwaters invertebrates of Russia and adjacent territories. (Vol. 2, pp. 1-629).

Tsalolikhin, S.Ya. (Ed.). (2016). Key to freshwaters zooplankton and zoobenthos of European Russia. (Vol. 2,. pp. 1-457).

Tsirtsis, G., \& Karydis, M. (1997). Aquatic microcosms: a methodological approach for the quantification of eutrophication processes. Environ Monit Assess, 48 (2), 193-215. https://doi.org/10.1023/A:1005756704615

Wijnhoven, S., Van Riel, M. C., Velde, G. (2003). Exotic and indigenous freshwater gammarid species: Physiological tolerance to water temperature in relation to ionic content of the water. Aquatic Ecology, 37(2), 151-158. DOI:10.1023/A:1023982200529

Zhadin, V. I. (1960). Methods of hydrobiological research. Vysshaya shkola. 